\title{
Procedural efficacy and safety of standardized, Ablation Index guided fixed 50W high power short duration pulmonary vein isolation and substrate modification using the CLOSE protocol
}

\author{
Alexander Francke ${ }^{1}$, Nadja Taha ${ }^{1}$, Frank Scharfe ${ }^{1}$, Steffen Schoen ${ }^{1}$, Carsten Wunderlich $^{1}$, \\ and Marian Christoph ${ }^{2}$ \\ ${ }^{1}$ HELIOS Klinikum Pirna \\ ${ }^{2}$ Klinikum Chemnitz - MEDIC
}

April 10, 2021

\begin{abstract}
Introduction: Ablation Index guided ablation according to the CLOSE protocol is very effective in terms of chronic pulmonary vein isolation (PVI). However, the optimal RF power remains controversial. Here, we thought to investigate the efficiency and safety of an AI guided fixed circumferential 50W high power short duration (HPSD) PVI using the CLOSE protocol Methods and results: In a single-centre prospective "proof of concept" trial 40 patients underwent randomized PVI using AI guided RF ablation without oesophageal temperature monitoring. In 20 patient fixed 50W HPSD was used irrespective to the anatomical localization. 20 subjects were ablated with standard power settings (20W posterior and $40 \mathrm{~W}$ roof and anterior wall). Additionally, 80 consecutive patients were treated according to the HPSD protocol to gather additional safety data. All patients underwent post-procedural oesophago-gastro-duodenoscopy to reveal oesophageal lesions (EDEL). The mean total procedural time was $80.3 \pm 22.5$ minutes in HPSD compared to control 109.1 $\pm 27.4(\mathrm{p}<0.001)$. The total RF-time was significantly lower in HPSD $1379 \pm 505 \mathrm{sec}$ vs. control $2374 \pm 619 \mathrm{sec}(\mathrm{p}<0.001)$. There were no differences in periprocedural complications. EDEL occurred in $13 \%$ in the HPSD and $10 \%$ in control group. EDEL occurring in the 50W HSDP patients were smaller, more superficial and had a faster healing tendency. Conclusions: A fixed 50W HPSD circumferential PVI relying to the ablation index and CLOSE protocol reduces the total procedure time and the total RF time compared to standard CLOSE protocol, without increasing the complication rates. The incidence of oesophageal lesions was similar using $50 \mathrm{~W}$ at the posterior atrial wall.
\end{abstract}

Procedural efficacy and safety of standardized, Ablation Index guided fixed 50W high power short duration pulmonary vein isolation and substrate modification using the CLOSE protocol A. Francke ${ }^{1}$ MD, N.S. Taha ${ }^{1}$, F. Scharfe ${ }^{1}$, S. Schoen ${ }^{1}$ MD, C. Wunderlich ${ }^{1}$ MD, M.Christoph ${ }^{2}$ MD

${ }^{1}$ Helios Klinikum Pirna, Struppener Str. 13, 01797 Pirna, Germany

${ }^{2}$ Klinikum Chemnitz - MEDiC, Flemmingstraße 2, 09116 Chemnitz, Germany

\section{Address for correspondence:}

Dr. Alexander Francke

Helios Klinikum Pirna

Struppener Str. 13, 01797, Pirna, Germany

Tel.: +49350171185067

Fax.: +49 350171185042 
Email: alexander.francke@helios-gesundheit.de

Manuscript information: 2 figures and 4 tables.

Word count: Abstract, 248; total manuscript 3451.

Disclosures: all other authors report no conflicts of interest. No financial support by third-parties or any grand was received. The data that support the findings of this study are available from the corresponding author upon reasonable request. The current study was a single-centre prospective trial performed in compliance with the guidelines for good clinical practice and the Declaration of Helsinki. The study was approved by the institutional ethical review board. All data were collected, managed and analysed at the Klinikum Pirna (ethics votum University of Dresden: EK 28409202). All patients provided informed consent.

\begin{abstract}
Introduction: Ablation Index guided ablation according to the CLOSE protocol is very effective in terms of chronic pulmonary vein isolation (PVI). However, the optimal RF power remains controversial. Here, we thought to investigate the efficiency and safety of an AI guided fixed circumferential $50 \mathrm{~W}$ high power short duration (HPSD) PVI using the CLOSE protocol
\end{abstract}

Methods and results: In a single-centre prospective "proof of concept" trial 40 patients underwent randomized PVI using AI guided RF ablation without oesophageal temperature monitoring. In 20 patient fixed 50W HPSD was used irrespective to the anatomical localization. 20 subjects were ablated with standard power settings (20W posterior and 40W roof and anterior wall). Additionally, 80 consecutive patients were treated according to the HPSD protocol to gather additional safety data. All patients underwent post-procedural oesophago-gastro-duodenoscopy to reveal oesophageal lesions (EDEL).

The mean total procedural time was $80.3 \pm 22.5$ minutes in HPSD compared to control 109.1 $\pm 27.4(\mathrm{p}<0.001)$. The total RF-time was significantly lower in HPSD $1379 \pm 505 \mathrm{sec}$ vs. control $2374 \pm 619 \mathrm{sec}(\mathrm{p}<0.001)$. There were no differences in periprocedural complications. EDEL occurred in 13\% in the HPSD and $10 \%$ in control group. EDEL occurring in the 50W HSDP patients were smaller, more superficial and had a faster healing tendency.

Conclusions: A fixed 50W HPSD circumferential PVI relying to the ablation index and CLOSE protocol reduces the total procedure time and the total RF time compared to standard CLOSE protocol, without increasing the complication rates. The incidence of oesophageal lesions was similar using $50 \mathrm{~W}$ at the posterior atrial wall.

\title{
Introduction
}

Creating of sustainable ablation lesions is the key for successful chronic pulmonary vein isolation using RFAblation. For this purpose, different objective parameter like the impedance drop, reduction in unipolar und bipolar voltage, the force time integral or the ablation index (AI) were established ${ }^{1,2}$. In this context, the ablation index (AI, Biosense Webster Inc), combining RF power, ablation-time, contact force, and catheter stability in a weighted, non-linear formula, was well validated in the close protocol in a prospective outcome trial $^{3,4}$. An ablation index between 400 and 550 in dependence of the anatomical location has been developed as standard of care, enabling reliable and reproducible pulmonary vein isolation (PVI) as described by Taghji and Duytschaever et al in the CLOSE protocol ${ }^{4,5}$. However, there is an ongoing discussion regarding the optimal RF power to achieve the required AI in the most effective and safest way. While conventional PVI is commonly performed using $20-30 \mathrm{~W}$ on the thin posterior atrial wall in proximity to the oesophagus to avoid thermal injury, 30-40W are used on the thicker anterior wall and atrial roof. However, there is growing evidence that high power short duration energy application (HPSD) relying on the ablation index might be as efficient, safe, and durable, whilst shortening procedure time ${ }^{6,7}$.

Here, we thought to compare the standard energy delivery with an ablation protocol of fixed high power 50W setting, both for circumferential PVI as well as additional lesion sets, guided by AI and the close-protocol to achieve durable PVI. 


\section{Methods}

Study Design

The current study was a single-centre prospective trial performed in compliance with the guidelines for good clinical practice and the Declaration of Helsinki. The study was approved by the institutional ethical review board. All data were collected, managed and analysed at the Klinikum Pirna (ethics votum University of Dresden: EK 28409202).

All eligible consecutive symptomatic AF patients referred for first time ablation of AF were included between April and November of 2020. An informed consent into the procedure was given by all patients.

The primary efficiency endpoints of this study were the differences of total procedural time, the total RF application-time and the time to PV isolation in the AI guided fixed HPSD protocol compared to the standard CLOSE-protocol.

The secondary efficiency endpoints were the number of required RF lesions, RF time per lesion, number of patients with first pass PV isolation and the AF recurrence rate within the first 12 weeks after the ablation procedure.

The primary safety endpoint was the number and characteristics of thermal oesophageal lesions using the fixed HPSD protocol compared to the standard CLOSE-protocol.

The secondary safety endpoint was the occurrence of procedural related complications other then thermal oesophageal lesions using the fixed HPSD protocol compared to the standard CLOSE-protocol.

\section{Study Population and protocol}

Eligible subjects were consecutive male or females $>18$ years of age suffering from symptomatic drug resistant atrial fibrillation (AF) requiring catheter ablation. No other inclusion criteria were necessary. Exclusion criteria was the refusal of the post-interventional esophago-gastro-duodenoscopy (EGD). If subjects fulfilled all inclusion criteria and none of the exclusion criteria, they were randomized either to the fixed HPSD protocol or to the standard CLOSE-protocol.

After randomization of 40 patients further 80 patients were treated with the fixed HPSD protocol to increase the validity of the primary safety endpoint in the fixed HPSD group.

The clinical data, intraprocedural data and complications were analyzed of all study subjects. Three experienced operators performed all ablation procedures.

\section{Ablation procedure}

AF ablations were performed by a standardized approach: Patients underwent the procedure in deep analgosedation with midazolam, fentanyl and propofol under invasive radial blood pressure monitoring. Groin-access was achieved using two 6 french and one 12 french venous sheaths. Diagnostic right ventricle and coronary sinus catheters were placed in all patients. A single transseptal puncture was guided by fluoroscopy using Abbott agilis medium curve sheaths and a Abbott BRK needle, followed by ACT-guided heparin treatment.

All procedures were guided by the Biosense Webster Inc. Carto3 v7 mapping system with univu-fluoroscopy integration. Left atrial angiograms were recorded under rapid pacing. Left atrial electro-anatomical reconstruction was done using Biosense Lasso catheters and the Carto3 V7 confidense module, with low-voltage settings for substrate mapping as previously described ${ }^{8,9}$.

PVI was performed in all patients. Additional lesion sets based on substrate homogenisation and blockisolation were performed when deemed necessary as previously described ${ }^{10}$. Ablation of the cavo-tricuspid isthmus was performed when right-atrial flutter was previously documented or induced during the procedure. All ablations were performed using the Biosense Webster SmartTouch SurroundFlow (ST-SF) ablation catheter and the Biosense Webster Smart-Ablate RF generator. Saline irrigations was performed as recommended by the manufacturer $(<30 \mathrm{~W} 8 \mathrm{ml} / \mathrm{s},>30 \mathrm{~W} 15 \mathrm{ml} / \mathrm{s})$. 
Ablation lesions were guided by the ablation-index module, with procedural guidelines and tag-settings previously described and validated in the CLOSE protocol ${ }^{4}$. Briefly, AI targets of 400 and 550 were used for posterior and anterior lesions, respectively, with an inter-lesion-distance (ILD) of $<6 \mathrm{~mm}$ and VisiTag size of $3 \mathrm{~mm}$. Catheter stability was set to $10 \mathrm{~mm}$, with force above threshold for $>25 \%$ of the time, and minimal stability for 3 seconds. In the control group the AI was reached with variable power in dependence of the anatomy (posterior and inferior wall $20 \mathrm{~W}$, roof and anterior wall $40 \mathrm{~W}$ ). In the HPSD group the AI was reached with a fixed high power of $50 \mathrm{~W}$ independently of the anatomical location.

After completion of all ablation sets and documented entrance and exit blocks, as well as bidirectional block of all additional lines, inducibility of sustained atrial tachycardia was tested by atrial high-rate burst and ramp stimulation.

CTI lesions were formed with $40 \mathrm{~W}$ in both groups. Periprocedural oesophageal temperature monitoring was not performed.

follow up

Directly after the ablation procedure and 24 hours after the ablation a neurological examination was conducted. Additionally, within 24 hours after the ablation procedure the access sites were clinically examined. Oesophago-gastro-duodenoscopy (EGD) was performed 24 hours after ablation procedure. Thermal oesophageal lesions were classified using the Kansas City Classification (KCC) ${ }^{11}$ and echocardiography were performed the day after the procedure in all patients. In case of documented thermal lesions, follow-up and treatment were carried out as planned by the treating physician. In the absence of oesophageal lesions, a PPI treatment of $20 \mathrm{mg}$ pantoprazol for 4 weeks was recommended. Early AF recurrence was defined as clinical relevant $\mathrm{AF}$ episode or documentation of AF in occasional ECG within the first 12 weeks after ablation procedure (patient- and primary physician reported outcome data).

\section{Statistical analysis}

Data were tested for normal distribution. Results of continuous variables are expressed as means \pm standard deviation. Statistical analyses were done using the 2 tailed, unpaired Student's t-test. Level of significance was set to $\mathrm{p}<0.05$. Categorical variables are presented as total number with comparison using chi-square statistics and Fisher exact test. Significance level was set to $\mathrm{p}<0.05$.

\section{Results}

\section{baseline and periprocedural characteristics}

The baseline characteristics of the study population are shown in table 1. Briefly, both treatment groups did not differ in mean age, left-ventricular function, EHRA stage, CHA2DS2-VASc and concomitant antiarrhythmic medication. However, the sex distribution differed slightly in both groups.

PVI was achieved in all 120 patients. First-pass isolation was achieved more often in the HPSD group, resulting in fewer additional touch-up lesions to close the remaining gaps, especially to the right pulmonary veins. In case of the existence of low voltage areas within the posterior, anterior, lateral or roof wall of the left atrium, additional ablation lines were created in order to isolate these scar areas. As shown in Table 2, the occurrence and treatment of low voltage areas did not differ between the two groups. Additional ablation of the cavo-tricuspid isthmus was performed in $55 \%$ of the patients in the control group and $66 \%$ of patients in the HPSD group.

primary efficiency endpoints

The primary efficiency endpoints are illustrated in figure 1 . The total procedural time was significantly lower in the HPSD group compared to the standard group (HPSD: $80.3 \pm 22.5$ minutes, control: $109.1 \pm 27.4$ minutes; $\mathrm{p}<0.001$ ). This result was primarily triggered by a significantly reduced total $\mathrm{RF}$ application time (HPSD: $1379 \pm 505 \mathrm{sec}$ vs. $2374 \pm 619 \mathrm{sec}$ vs. control; $\mathrm{p}<0.001$ ). Pulmonary vein isolation was achieved after $60.4 \pm 13.1$ minutes in the HPSD group compared to $78.6 \pm 8.9$ minutes in the control group $(\mathrm{p}<0.001)$. 


\section{secondary efficiency endpoints}

As shown in table 2, the number of RF lesions delivered for the total AF ablation procedure did not differ between the two treatment groups. In contrast, the RF time per lesion until the target AI was reached was significantly shorter in the HPSD group compared to the controls (HPSD: $18.5 \pm 3.4 \mathrm{sec}$ vs. control: $28 \pm$ $3.6 ; \mathrm{p}<0.001)$.

Early recurrence of atrial fibrillation within the first 12 weeks after ablation was reported in $25 \%$ in the control- and $6 \%$ in the HPSD group ( $\mathrm{p}=0.007$, patient- and primary physician reported outcome data).

thermal oesophageal lesions (primary safety endpoint)

Oesophageal thermal lesions were seen in 2 out of 20 patients (10\%) within the standard group and 13 out of 97 patients (13.4\%) in the HPSD group ( $\mathrm{p}=0.72$; table 3$)-3$ patients within the high-power group withdrew consent to perform the post-procedural EGD. The individual lesion characteristics are displayed in table 4. Lesions characteristics differed apparently between the two ablation groups. Both lesions seen in the standard-power group were typical thermal oesophageal lesions previously described after PVI, forming deep ulcerations during follow-up and showed slow regression tendencies starting 2 weeks after the index procedure (figure 2 panel A, B). The 13 lesions seen after HPSD ablation were overall smaller and more shallow: 5 lesions showed merely a detachment of superficial mucosal layers that resolved completely after one week (figure 2, panel C - E), 5 lesions showed small ulcer $<=5 \mathrm{~mm}$ that resolved within 7-14 days and one larger lesion $7 \mathrm{~mm}$ in diameter showed healing tendencies after 2 weeks of follow-up (figure 2, Panel F). One patient developed a large, superficial ulcer $12 \mathrm{~mm}$ in diameter, that was followed up over a course of 12 weeks and showed prolonged scarring healing, without evidence of fistula formation (supplemental figure, panel G),. Overall, only 2 out of $97(2 \%)$ of all HPSD treated patients developed clinical significant thermal injuries. HPSD Ablation to the inferior wall was not associated with an increase in EDEL, as only 2 out of 17 patients with additional inferior box lesions developed superficial EDEL (11.7\%, n.s.).

Periprocedural complications other than thermal oesophageal lesions (secondary safety endpoints)

Secondary safety endpoints are shown in table 3. Pericardial tamponade or vascular/groin complications did not occur in any of the therapy groups. One patient within the high-power group reported a transient episode of facial palsy, which resolved within minutes, and did not had any correlations in MR imaging. Discrete pericardial effusion was reported in two patients in the fixed HPSD group. One of these subjects developed Dressler's syndrome with polyserositis after extensive left-atrial ablation including extensive additional substrate modification with a resulting total RF-delivery-time of 2300 seconds. The symptoms and effusions resolved after 5 days on antiphlogistic treatment. These findings were statistically non-significant.

No steam pops occurred in the delivery of 1706 standard energy and 7462 high-power ablation lesions.

Chest pain was reported frequently after HPSD ablation, mostly described as breath dependant, starting 1-2 days after the procedure, lasting for 1-2 days in most patients. Some of these patients required antiphlogistic medication.

\section{Discussion}

This proof of concept study suggest that a standardized approach for AF ablation using circumferential high power $50 \mathrm{~W}$ setting guided by the ablation index, which was proofed in the CLOSE-protocol, was highly effective by reducing the total procedure time and $\mathrm{RF}$ application time, with low procedural complication rates, compared to the standard power settings. Especially in light of oesophageal lesions (EDEL), this study could not reveal increased rates of oesophageal lesions under ablation with $50 \mathrm{~W}$ at the posterior left atrial wall, compared to the standard power settings, even without oesophageal temperature monitoring. Of note, the oesophageal lesions occurring with the $50 \mathrm{~W}$ ablation were smaller, more superficial and had a faster healing tendency in comparison to the standard power settings. Further, fixed 50W AI-guided ablation did not result in any steam pops, increased incidence of pericardial tamponade or early AF recurrence rate compared to the standard power settings. The absence of steam-pops is remarkable, since Chen et al reported 
up to $8 \%$ steam-pop rates in comparable ablation settings. Close monitoring of impedance drop and stability during lesion formation, as well as avoiding excessive contact force and operator experience in a single-centre setting might have contributed.

Sustainable RF lesions are the most important requirement for a durable PVI. Lesion formation is influenced by RF power, RF application time, catheter contact force and catheter stability ${ }^{6}$. Duytschaever and colleagues evaluated the ablation index in the CLOSE and close-to-cure study ${ }^{3,4}$. The AI combines the different above mentioned factors in a nonlinear weighted formula, in which the RF power has the greatest contribution. The resulting index seems to be very predictive for the lesion quality and quantity. Nonetheless, there is an ongoing discussion about the most important contributor of this index - the ideal RF power. Whereas most ablation centres use conventional power settings of $25-35 \mathrm{~W}$, some previous trials like the power-AF study showed that a $45 \mathrm{~W}$ RF-power CLOSE-protocol in paroxysmal AF patients significantly increases the global procedural efficiency with similar mid-term efficacy ${ }^{12}$. Other studies compared ablation protocols with very high power settings and short RF application time not relying on the ablation index: Deisenhofer et al. could show that a high power short-duration ablation using $70 \mathrm{~W}$ for $5-7 \mathrm{~s}$ leads to significantly less arrhythmia recurrences after 1 year and to significantly shortened RF- and procedural time ${ }^{13}$. In addition, the QDot-fast trial was able to show that an irrigated very high power short duration ablation (vHPSD: 90W/4s) is feasible and safe to achieve durable PVI in the most cases in a very short procedural- and fluoroscopy time 14. Of note, only in $78.8 \%$ of cases, PVI was achieved using the vHPSD mode only. Early PV reconnection occurred predominantly in the area of the posterior wall, requiring re-ablation with standard settings in some cases ${ }^{14}$. The biophysical background of the different RF power settings is the way in which the energy is delivered into the tissue. Using higher RF power (HPSD), the tissue heating is caused resistive as direct catheter-myocardium interaction and within the myocardium itself. This direct heating begins immediately and stops with the end of RF energy application ${ }^{6}$. Histological data shows that the resulting HPSD lesions differ compared to the standard RF power. In contrast, ablation with standard RF settings and a longer $\mathrm{RF}$ application time causes a conductive, i.e. indirect heating which transfers the energy as passive process to more distant tissue. This conductive heating continues, even after the RF power application has stopped and results in deeper lesions compared to $\mathrm{HPSD}^{6}$. Therefore, from a biophysical point of view, it is quite conceivable that HPSD ablation may cause less damage on neighbouring structures such as the oesophagus.

Here, procedural safety was high both in the standard and HPSD group, underlining the advances in atrial fibrillation procedures ${ }^{15}$. Chest pain was reported by almost ever second patient treated in the HPSD group, however, most patients reported merely minor discomfort and did not require pain medication or prolonged hospitalisation. The pain was mostly described as being breath dependant, i.e. pleuritic. Typically, the development of Dressler's syndrome is a rare complication after catheter ablation of $\mathrm{AF}^{16}$ - while the occurrence of Dressler's syndrome in one patient receiving HPSD PVI with extensive left atrial substrate modification might be coincidence, it will require further alert attention, since the mechanism of tissue damage differ between normal and HPSD ablation.

Recently, Sommer and colleagues could show in the OPERA trial that the peak oesophageal temperature during AF ablation was not predictive for the development of thermal oesophageal lesions ${ }^{17}$. In the present study no more EDEL could be detected compared to previously reported ablation studies, even without oesophageal temperature monitoring and HPSD ablation at the posterior wall ${ }^{17}$. While the overall incidence of EDEL was identical in the standard and HPSD ablation approach, lesion characteristics differed significantly, with most of the HPSD lesions consisting of small ulcerations or only superficial mucosal detachments that are poorly characterized in the currently used classification of EDEL ${ }^{11}$. These findings support the above mentioned biophysical considerations and are in line with previous publications of HPSD lesions ${ }^{18}$. In the present trial, all patients received post-procedural esophagoscopy and were followed up until the lesions resolved, or showed healing tendency. In further clinical practice, one might consider performing index esophagoscopy to characterise lesions. Smaller ulcerations or mucosal detachments are likely to resolve within 1-2 weeks, without the need for extensive follow-up, whereas patients with larger lesions might be monitored more intensively. However, there is little to no experience and evidence in the development of atrial-oesophageal fistula after HPSD ablation, and time-line characteristics might differ from 
fistula formation previously described for normal power ablation ${ }^{19,20}$. To avoid the development of EDEL while using HPSD at the posterior wall, the recommendations published in the power-AF study should be followed: avoiding high contact force and adapted stability criteria to avoid delayed appearance of the Visitag above the target AI value ${ }^{12}$. In our study, post-hoc analysis revealed that the largest EDEL occurred in a patient where some posterior points where achieved with a mean contact force of 24 and above grams, with maximum lesion AI of 430 on the posterior wall.

There are some limitations of the current study. First, the study was not designed as a mid-term or long-term outcome trial including re-ablation of patients suffering from AF recurrence. Thus, the long term durability of the ablation lesions, created with the AI guided 50W setting, as well as the resulting clinical outcome remains speculative in lack of robust follow-up data. Further, like in the previous trials the number of the studied subjects was too small to make a valid statement about the real incidence of atrial-oesophageal fistulas using the fixed $50 \mathrm{~W}$ power setting.

However, while most previous studies have used higher-power ablation with less than $50 \mathrm{~W}$, or with reduced power on the posterior wall to $<35 \mathrm{~W}$, or without relying on ablation index guidance, our study is the one of the first to perform circumferential 50W HPSD PVI with AI guidance and the CLOSE protocol, confirming the data of the FAFA AI High Power Study by Chen et al ${ }^{21}$ - but in contrast, without performing esophageal temperature monitoring, and including more complex left atrial procedures with an additional substrate based approach, even including 50W HPSD inferior wall isolation.

\section{Conclusions:}

A fixed 50W high power short duration circumferential PVI guided by the ablation index and CLOSE protocol reduces the total procedure time and the total RF time compared to standard CLOSE protocol, without increasing the complication rates. Especially the incidence of oesophageal lesions was similar using $50 \mathrm{~W}$ at the posterior atrial wall, even without oesophageal temperature monitoring. Of note, the oesophageal lesions occurring in the 50W HSDP patients were smaller, more superficial and had a faster healing tendency.

\section{Acknowledgements:}

We thank all staff of the EP-laboratory und EGD-laboratory, Klinikum Pirna for supporting this trial

\section{Funding Sources:}

This study was not supported by any grant.

\section{Disclosures:}

All other authors report no conflicts of interest.

Tables:

Table 1 Baseline characteristics

\begin{tabular}{|c|c|c|c|}
\hline & Standard $(\mathrm{N}=20)$ & $\operatorname{HPSD}(\mathrm{N}=100)$ & $\mathbf{P}$ \\
\hline $\begin{array}{l}\text { Age (mean } \pm \mathrm{SD}, \\
\text { min-max) }\end{array}$ & $66.4 \pm 10(45-80)$ & $66,4 \pm 10(35-80)$ & 0,99 \\
\hline Sex male female & $7 / 20(35 \%) \quad 13 / 20(65 \%)$ & $\begin{array}{l}60 / 100(60 \%) 40 / 100 \\
(40 \%)\end{array}$ & 0,04 \\
\hline $\begin{array}{l}\mathbf{L V}-\mathbf{E F}(\text { mean } \pm \mathrm{SD}, \\
\text { min-max) }\end{array}$ & $59.5 \pm 5.5(45-65)$ & $54.2 \pm 13.3(10-65)$ & 0,08 \\
\hline $\begin{array}{l}\text { AF type paroxysmal } \\
\text { persistent }\end{array}$ & $9 / 20(45 \%) 11 / 20(55 \%)$ & $49 / 100(49 \%) 51 / 100(51)$ & 0.74 \\
\hline $\begin{array}{l}\text { EHRA stage I: IIa: IIb: } \\
\text { III: IV: }\end{array}$ & $\begin{array}{l}0 / 20(0 \%) 1 / 20(5 \%) \\
5 / 20(25 \%) 11 / 20(55 \%) \\
3 / 20(15 \%)\end{array}$ & $\begin{array}{l}1 / 100(1 \%) 8 / 100(8 \%) \\
26 / 100(26 \%) 56 / 100 \\
(56 \%) 9 / 100(9 \%)\end{array}$ & 0.94 \\
\hline
\end{tabular}


CHA2DS2-VASc

(mean $\pm \mathrm{SD}$, min-max)

Medications

Betablockers Flecainide

Amiodarone
$3.2 \pm 1.5(1-6)$
$2.8 \pm 1.5(0-7)$
0,34
$19 / 20(95 \%) 1 / 20(5 \%)$
$89 / 100(89 \%) 6 / 100$
0.410 .860 .92
$5 / 20(25 \%)$
(6\%) $24 / 100(24 \%)$

Table 2 Procedural data and characteristics

\begin{tabular}{|c|c|c|c|}
\hline & Standard $(\mathrm{N}=20)$ & $\operatorname{HPSD}(\mathrm{N}=100)$ & $\mathbf{P}$ \\
\hline $\begin{array}{l}\text { fluoroscopy time } \\
\text { (min) }\end{array}$ & $1.6 \pm 0.8(0.6-4)$ & $1.8 \pm 1.4(0.5-13)$ & 0.52 \\
\hline map-volume (ml) & $107.5 \pm 21.6(65-158)$ & $97 \pm 20.5(66-150)$ & 0.09 \\
\hline $\begin{array}{l}\text { Number of required } \\
\text { RF lesions }\end{array}$ & $85.3 \pm 23.2(63-140)$ & $74.6 \pm 25.4(47-155)$ & 0.09 \\
\hline $\begin{array}{l}\text { RF time per RF } \\
\text { lesion (sec) }\end{array}$ & $28 \pm 3.6(23.3-37.7)$ & $18.5 \pm 3.4(14.1-43.6)$ & $<0.001$ \\
\hline $\begin{array}{l}\text { Low-voltage inferior } \\
\text { anterior lateral roof }\end{array}$ & $\begin{array}{l}2 / 20(10 \%) 4 / 20(20 \%) \\
1 / 20(5 \%) 1 / 20(5 \%)\end{array}$ & $\begin{array}{l}17 / 100(17 \%) 17 / 100 \\
(17 \%) 2 / 100(2 \%) \\
10 / 100(10 \%)\end{array}$ & $\begin{array}{llll}0.43 & 0.74 & 0.43 & 0.48\end{array}$ \\
\hline CTI & $11 / 20(55 \%)$ & $66 / 100(66 \%)$ & 0.35 \\
\hline First Pass LPV RPV & $\begin{array}{l}17 / 20(85 \%) 10 / 20 \\
(50 \%)\end{array}$ & $\begin{array}{l}95 / 100(95 \%) 84 / 100 \\
(84 \%)\end{array}$ & $0.12<0.001$ \\
\hline Early AF recurrence & $5 / 20(25 \%)$ & $6 / 100(6 \%)$ & 0.007 \\
\hline Inducibility & $2 / 20(20 \%)$ & $4 / 100(4 \%)$ & 0.26 \\
\hline
\end{tabular}

Table 3 procedural complications

\begin{tabular}{llll}
\hline & Standard $(\mathbf{N}=\mathbf{2 0})$ & HPSD $(\mathbf{N}=100)$ & $\mathbf{P}$ \\
primary safety endpoint & primary safety endpoint & $\begin{array}{l}\text { primary safety endpoint } \\
\text { primary safety endpoir }\end{array}$ & $\begin{array}{l}0.72 \\
\text { Oesophageal lesion }\end{array}$ \\
secondary safety endpoint & $2 / 20(10 \%)$ & $13 / 97(13.4 \%)$ & secondary safety endpoint \\
secondary safety endpoint & secondary safety endp \\
Chest pain & $1 / 20(5 \%)$ & $48 / 100(48 \%)$ & $<0.001$ \\
Neurological & None & $1 / 100(\mathrm{TIA})$ & 0.65 \\
Pericardial effusion & None & $2 / 100$ & 0.52 \\
Pericardial tamponade & None & None & - \\
Steam pops & $0 / 1706 \mathrm{RF}$ tags & $0 / 7462 \mathrm{RF}$ tags & - \\
Vascular & $0 / 20(0 \%)$ & $0 / 100(0 \%)$ & - \\
\hline
\end{tabular}

Table 4 Individual lesion characteristics

\begin{tabular}{lllllll}
\hline & $\begin{array}{l}\text { Inferior Low } \\
\text { voltage }\end{array}$ & $\begin{array}{l}\text { Esophageal } \\
\text { lesion char- } \\
\text { acteristics }\end{array}$ & KCC & $\begin{array}{l}\text { Time to } \\
\text { regression }\end{array}$ & PPI & Antibiotics \\
Std. & Severe $8 \mathrm{~mm}$ & $2 \mathrm{~b}$ & 21 days & $2 \times 40 \mathrm{mg} 8$ \\
& ulceration, \\
& slowly & & & \\
& resolving after & & & \\
& 2 weeks & & &
\end{tabular}




\begin{tabular}{|c|c|c|c|c|c|c|}
\hline Std. & - & $\begin{array}{l}\text { Severe } 10 \mathrm{~mm} \\
\text { ulceration of } \\
10 \mathrm{~mm} \text {, slowly } \\
\text { resolving after } \\
2 \text { weeks }\end{array}$ & $2 b$ & 21 days & $\begin{array}{l}2 \mathrm{x} 40 \mathrm{mg} 8 \\
\text { weeks }\end{array}$ & \\
\hline HPSD & - & $\begin{array}{l}3 \mathrm{~mm} \\
\text { erythema }\end{array}$ & 1 & 4 days & $\begin{array}{l}2 \times 40 \mathrm{mg} 4 \\
\text { weeks }\end{array}$ & \\
\hline HPSD & - & $\begin{array}{l}3 \mathrm{~mm} \\
\text { ulceration }\end{array}$ & $2 \mathrm{a}$ & 7 days & $\begin{array}{l}2 \mathrm{x} 40 \mathrm{mg} 4 \\
\text { weeks }\end{array}$ & \\
\hline HPSD & - & $\begin{array}{l}\text { Two } \\
\text { ulcerations, } 3 \\
\text { mm each }\end{array}$ & $2 \mathrm{a}$ & 7 days & $\begin{array}{l}2 \mathrm{x} 40 \mathrm{mg} 4 \\
\text { weeks }\end{array}$ & \\
\hline HPSD & - & $\begin{array}{l}3 \mathrm{~mm} \text { mucosal } \\
\text { detatchment }\end{array}$ & $2 \mathrm{a}$ & 7 days & $\begin{array}{l}2 \times 40 \mathrm{mg} 4 \\
\text { weeks }\end{array}$ & $\begin{array}{l}\text { Amoxicilin } 5 \\
\text { days }\end{array}$ \\
\hline HPSD & + & $\begin{array}{l}5 \mathrm{~mm} \\
\text { ulceration }\end{array}$ & $2 \mathrm{a}$ & 14 days & $\begin{array}{l}2 \mathrm{x} 40 \mathrm{mg} 4 \\
\text { weeks }\end{array}$ & \\
\hline HPSD & - & $\begin{array}{l}7 \mathrm{~mm} \\
\text { ulceration, } \\
\text { healing } \\
\text { tentency after } \\
14 \text { days of } \\
\text { followup }\end{array}$ & $2 \mathrm{a}$ & $>14$ days & $\begin{array}{l}2 \times 40 \mathrm{mg} 4 \\
\text { weeks }\end{array}$ & \\
\hline HPSD & - & $\begin{array}{l}\text { Tiny mucosal } \\
\text { detachment }\end{array}$ & 1 & $\begin{array}{l}\text { no EGD } \\
\text { follow-up }\end{array}$ & $\begin{array}{l}2 \mathrm{x} 40 \mathrm{mg} 4 \\
\text { weeks }\end{array}$ & \\
\hline HPSD & + & $\begin{array}{l}\text { Tiny mucosal } \\
\text { detachment }\end{array}$ & 1 & 7 days & $\begin{array}{l}2 \mathrm{x} 40 \mathrm{mg} 4 \\
\text { weeks }\end{array}$ & \\
\hline HPSD & - & $\begin{array}{l}\text { Severe } 12 \mathrm{~mm} \\
\text { ulceration, } \\
\text { very slowy } \\
\text { resolving }\end{array}$ & $2 \mathrm{~b}$ & 12 weeks & $\begin{array}{l}2 \times 40 \text { mg } 8 \\
\text { weeks, } 2 \text { x20 } \\
\text { mg } 4 \text { weeks }\end{array}$ & $\begin{array}{l}\text { Amoxicilin } 4 \\
\text { weeks }\end{array}$ \\
\hline HPSD & - & $\begin{array}{l}3 \text { tiny mucosal } \\
\text { detachments }\end{array}$ & $2 \mathrm{a}$ & $\begin{array}{l}\text { no EGD } \\
\text { follow-up }\end{array}$ & $\begin{array}{l}2 \times 40 \mathrm{mg} 4 \\
\text { weeks }\end{array}$ & \\
\hline HPSD & - & $\begin{array}{l}3 \mathrm{~mm} \text { mucosal } \\
\text { detachment }\end{array}$ & $2 \mathrm{a}$ & $\begin{array}{l}\text { no EGD } \\
\text { follow-up }\end{array}$ & $\begin{array}{l}2 \times 40 \mathrm{mg} 4 \\
\text { weeks }\end{array}$ & \\
\hline HPSD & - & $\begin{array}{l}\text { Linear mucosal } \\
\text { detachment, } \\
\text { later one } \\
\text { singular } 5 \mathrm{~mm} \\
\text { ulceration, } \\
\text { healed after } 14 \\
\text { days }\end{array}$ & $2 \mathrm{a}$ & 14 days & $\begin{array}{l}2 \times 40 \mathrm{mg} 4 \\
\text { weeks }\end{array}$ & \\
\hline HPSD & - & $\begin{array}{l}3 \mathrm{~mm} \\
\text { ulceration }\end{array}$ & $2 \mathrm{a}$ & 7 days & $\begin{array}{l}2 \mathrm{x} 40 \mathrm{mg} 4 \\
\text { weeks }\end{array}$ & \\
\hline
\end{tabular}




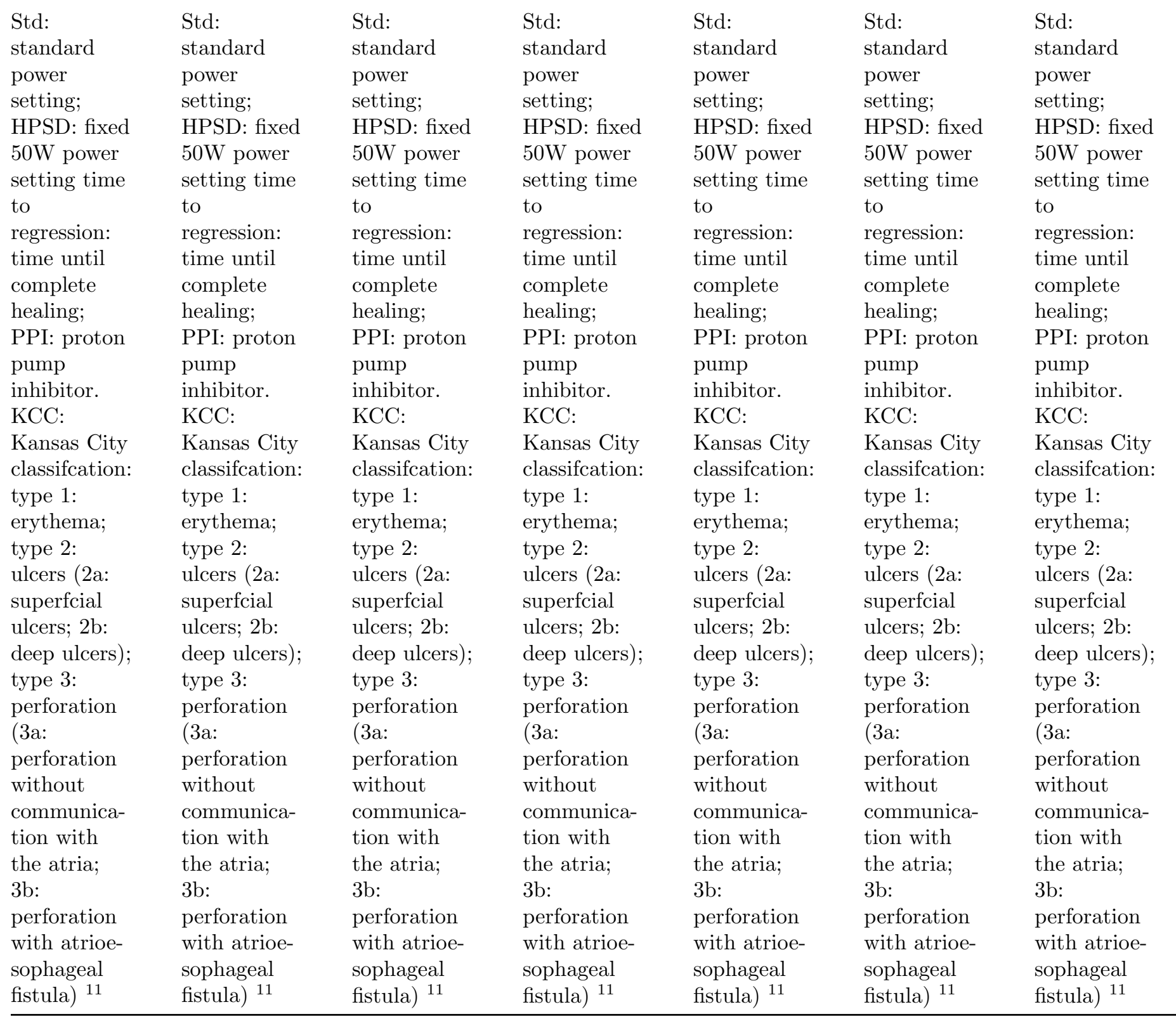




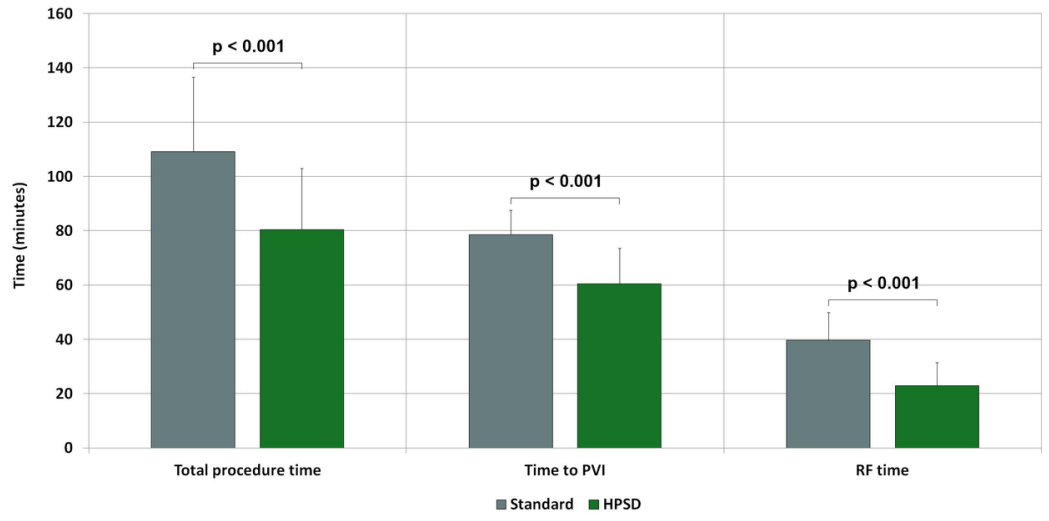

Figure 1 total procedural time, time to PVI, and RF time (primary endpoint) 

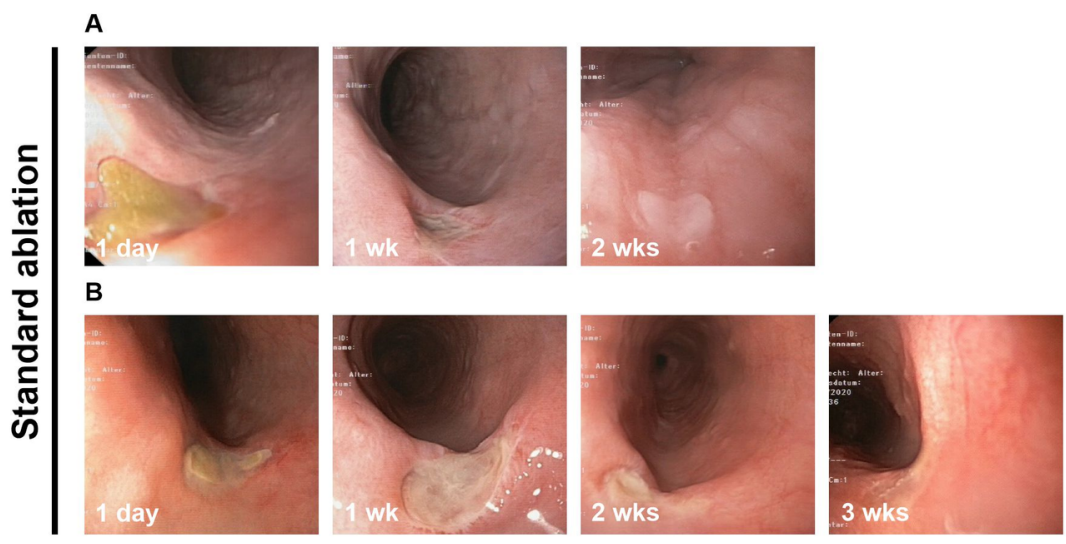

C

D
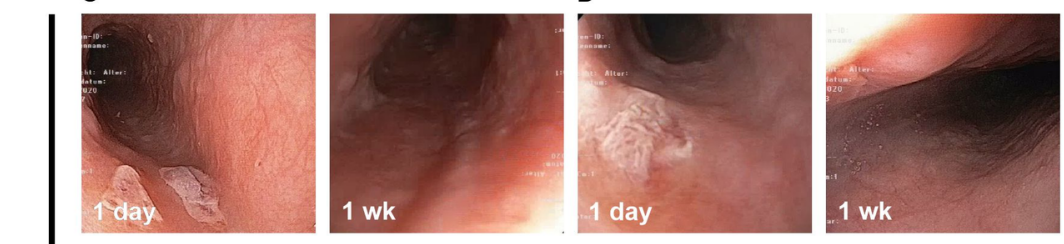

E

$\mathbf{F}$
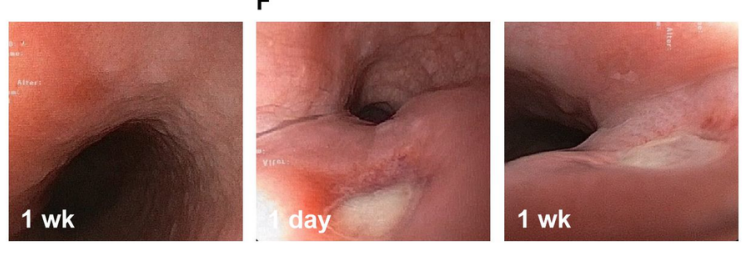

G
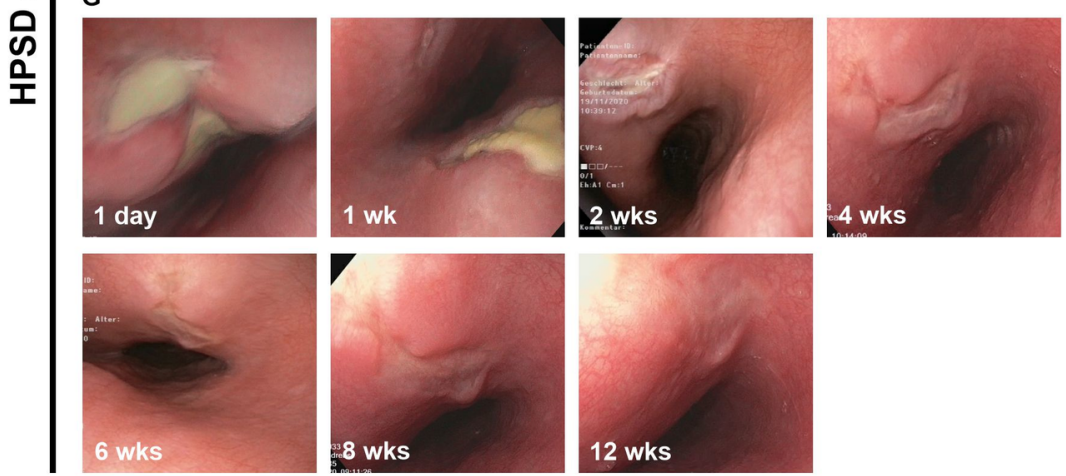

Figure 2: Thermal oesophageal lesions - representative figures

\section{Figure legend:}

figure 1: total procedural time, time to PVI, and RF time (primary endpoint)

Standard: AI guided PVI using standard power settings according to the CLOSE-protocol; HPSD AI guided PVI using fixed 50W power setting relying to the CLOSE-protocol; total procedure time: time from groin puncture to bandage; time to PVI: time from groin puncture to complete electrical isolation of the pulmonary veins; $\mathrm{RF}$ time: total radio frequency application time (data presented as mean $\pm \mathrm{SEM}, \mathrm{p}<0.05$ was defined as significant) 
figure 2 : Thermal oesophageal lesions - representative figures

time course of thermal oesophageal lesions visualized with EGD

Standard ablation: A and B: typical deep ulcerations with slow healing tendencies.

HPSD Ablation: C-E superficial mucosal detachment; F typical ulcer (KCC 2a) with healing tendencies after one week; $\mathrm{G}$ deep, fibrin covered ulceration (KCC 2b) with very slow scarring healing over 12 weeks

\section{References}

1. Das M, Loveday JJ, Wynn GJ, Gomes S, Saeed Y, Bonnett LJ, et al. Ablation index, a novel marker of ablation lesion quality: prediction of pulmonary vein reconnection at repeat electrophysiology study and regional differences in target values. EP Europace 2017;19:775-83.

2. Hussein A, Das M, Riva S, Morgan M, Ronayne C, Sahni A, et al.Use of Ablation Index-Guided Ablation Results in High Rates of Durable Pulmonary Vein Isolation and Freedom From Arrhythmia in Persistent Atrial Fibrillation Patients: The PRAISE Study Results. Circ Arrhythm Electrophysiol 2018;11 :e006576.

3. Duytschaever M, De Pooter J, Demolder A, El Haddad M, Phlips T, Strisciuglio T, et al. Long-term impact of catheter ablation on arrhythmia burden in low-risk patients with paroxysmal atrial fibrillation: The CLOSE to CURE study. Heart Rhythm2020;17:535-43.

4. Taghji P, El Haddad M, Phlips T, Wolf M, Knecht S, Vandekerckhove Y,et al. Evaluation of a Strategy Aiming to Enclose the Pulmonary Veins With Contiguous and Optimized Radiofrequency Lesions in Paroxysmal Atrial Fibrillation: A Pilot Study. JACC Clin Electrophysiol2018;4:99-108.

5. Duytschaever M, Vijgen J, De Potter T, Scherr D, Van Herendael H, Knecht S, et al. Standardized pulmonary vein isolation workflow to enclose veins with contiguous lesions: the multicentre VISTAX trial.Europace $2020 ; 22: 1645-52$.

6. Kotadia ID, Williams SE, O'Neill M. High-power, Short-duration Radiofrequency Ablation for the Treatment of AF. Arrhythm Electrophysiol Rev 2020;8 :265-72.

7. Berte B, Hilfiker G, Russi I, Moccetti F, Cuculi F, Toggweiler S, et al. Pulmonary vein isolation using a higher power shorter duration CLOSE protocol with a surround flow ablation catheter. $J$ Cardiovasc Electrophysiol 2019;30:2199-204.

8. Huo Y, Gaspar T, Pohl M, Sitzy J, Richter U, Neudeck S, et al.Prevalence and predictors of low voltage zones in the left atrium in patients with atrial fibrillation. Europace2018;20:956-62.

9. Verma A, Wazni OM, Marrouche NF, Martin DO, Kilicaslan F, Minor S, et al. Pre-existent left atrial scarring in patients undergoing pulmonary vein antrum isolation: an independent predictor of procedural failure. J Am Coll Cardiol 2005;45 :285-92.

10. Rolf S, Kircher S, Arya A, Eitel C, Sommer P, Richter S, et al. Tailored atrial substrate modification based on low-voltage areas in catheter ablation of atrial fibrillation. Circ Arrhythm Electrophysiol 2014;7 :825-33.

11. Yarlagadda B, Deneke T, Turagam M, Dar T, Paleti S, Parikh V, et al. Temporal relationships between esophageal injury type and progression in patients undergoing atrial fibrillation catheter ablation. Heart Rhythm 2019;16 :204-12.

12. Wielandts J-Y, Kyriakopoulou M, Almorad A, Hilfiker G, Strisciuglio T, Phlips T, et al. Prospective Randomized Evaluation of High Power During CLOSE-Guided Pulmonary Vein Isolation: The POWER-AF Study. Circ Arrhythm Electrophysiol 2021;14 :e009112.

13. Kottmaier M, Popa M, Bourier F, Reents T, Cifuentes J, Semmler V,et al. Safety and outcome of very high-power short-duration ablation using $70 \mathrm{~W}$ for pulmonary vein isolation in patients with paroxysmal atrial fibrillation. Europace $2020 ; 22: 388-93$. 
14. Reddy VY, Grimaldi M, De Potter T, Vijgen JM, Bulava A, Duytschaever MF, et al. Pulmonary Vein Isolation With Very High Power, Short Duration, Temperature-Controlled Lesions: The QDOT-FAST Trial.JACC Clin Electrophysiol 2019;5:778-86.

15. Gupta A, Perera T, Ganesan A, Sullivan T, Lau DH, Roberts-Thomson KC, et al. Complications of catheter ablation of atrial fibrillation: a systematic review. Circ Arrhythm Electrophysiol2013;6 :1082-8.

16. Luckie M, Jenkins NP, Davidson NC, Chauhan A. Dressler's syndrome following pulmonary vein isolation for atrial fibrillation. Acute Card Care 2008;10:234-5.

17. Schoene K, Arya A, Grashoff F, Knopp H, Weber A, Lerche M, et al. Oesophageal Probe Evaluation in Radiofrequency Ablation of Atrial Fibrillation (OPERA): results from a prospective randomized trial.Europace 2020;22 :1487-94.

18. Kaneshiro T, Kamioka M, Hijioka N, Yamada S, Yokokawa T, Misaka T, et al. Characteristics of Esophageal Injury in Ablation of Atrial Fibrillation Using a High-Power Short-Duration Setting. Circ Arrhythm Electrophysiol 2020;13 :e008602.

19. Kapur S, Barbhaiya C, Deneke T, Michaud GF. Esophageal Injury and Atrioesophageal Fistula Caused by Ablation for Atrial Fibrillation. Circulation 2017;136 :1247-55.

20. Halbfass P, Pavlov B, Müller P, Nentwich K, Sonne K, Barth S, et al. Progression From Esophageal Thermal Asymptomatic Lesion to Perforation Complicating Atrial Fibrillation Ablation: A Single-Center Registry. Circ Arrhythm Electrophysiol 2017;10 .

21. Chen S, Schmidt B, Bordignon S, Urbanek L, Tohoku S, Bologna F, et al. Ablation index-guided $50 \mathrm{~W}$ ablation for pulmonary vein isolation in patients with atrial fibrillation: Procedural data, lesion analysis, and initial results from the FAFA AI High Power Study. Journal of Cardiovascular Electrophysiology2019;30 $: 2724-31$. 